\title{
Effects of finish turning on an austenitic weld investigated using diffraction methods
}

\author{
J. Rebelo Kornmeier ${ }^{1}$ (D) M. Hofmann ${ }^{1} \cdot$ W. M. Gan ${ }^{2}$ (D) - V. Robin ${ }^{3} \cdot$ F. Valiorgue ${ }^{4} \cdot$ H. Pascal ${ }^{4}$. J. Gibmeier ${ }^{5}$ (D) \\ J. Saroun 6
}

Received: 13 December 2019 / Accepted: 29 April 2020 / Published online: 18 May 2020

(C) The Author(s) 2020

\begin{abstract}
Arc welding generally introduces undesired local residual stress states on engineering components hindering high-quality performance in service. Common procedures to reduce the tensile residual stresses are post-heat treatments or mechanical surface treatments like hammering or shot-peening. Assessments of residual stress profiles of post-weld treatments underneath the weld surface are essential, especially in high safety exigency systems like pressure vessels or piping at power plants. In this study, neutron diffraction is used to determine the stress profile after finish milling of an austenitic steel weld in order to verify a chained finite element simulation predicting the final residual stress fields including milling and welding contributions. Non-destructive measurements with spatial resolutions of less than $0.2 \mathrm{~mm}$ within the first $1 \mathrm{~mm}$ from the surface were mandatory to confirm the finite element simulations of the coarse-grained austenitic material. In the data analysis procedure, the obtained near-surface data have been corrected for spurious strain effects whenever the gauge volume was partially immersed in the sample. Moreover, constraining the surface data to values obtained by $x$-ray diffraction and data deconvolution within the gauge volume enabled access of the steep residual stress profile within the first $1 \mathrm{~mm}$.
\end{abstract}

Keywords AISI316 $\cdot$ Weld $\cdot$ Finish milling $\cdot$ Residual stresses $\cdot$ Non-destructive neutron diffraction

\section{Introduction}

Welding is one of the most important processes to join components ranging from simple and small engineering applications to huge and high safety exigence such as pressure vessels or piping in power plants. Tensile residual stresses usually associated with welded joints are a problem in optimum exploitation of engineering structures as they may

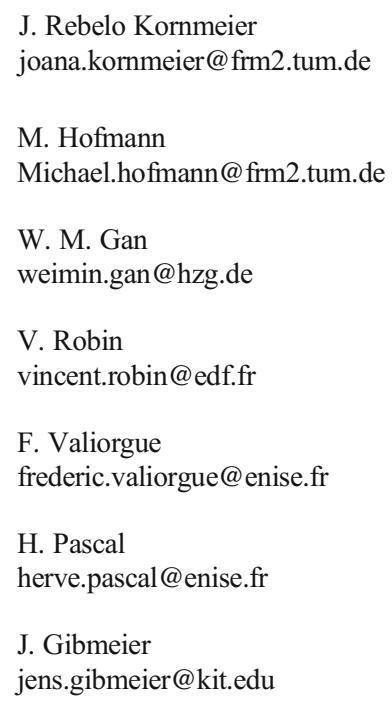

J. Saroun

saroun@ujf.cas.cz

1 Heinz Maier-Leibnitz Zentrum (MLZ) FRM II, Technische Universität München, Lichtenbergstr. 1, Garching b., 85748 München, Germany

2 German Engineering Materials Centre at MLZ, Helmholtz-Zentrum Geesthacht, Lichtenbergstr. 1, Garching b., 85748 München, Germany

3 Département PRISME - Performance, Risque Industriel, Surveillance pour la Maintenance et l'Exploitation, EDF - R\&D, 6, quai Watier, 78401 Chatou Cedex, France

4 LTDS/ENISE, 58 Rue Jean Parot, 42100 Saint Étienne, France

5 KIT - Karlsruhe Institute of Technology, Institute for Applied Materials, Kaiserstr. 12, 76131 Karlsruhe, Germany

6 Nuclear Physics Institute of the CAS, v.v.i., 250 68 Rez, Czech Republic 
compromise structural integrity and limit the component life. In service, applied loads superimpose onto the residual stresses reducing considerably the component fatigue resistance if they are tensile in nature. Several methods of mechanical as well as thermal treatments - in situ and post-welding - exist, reducing detrimental tensile stresses or even introducing beneficial compressive residual stresses [1]. While some of these methods, for instance peening, affect primarily the nearsurface material condition [2], others like thermal treatments may influence the residual stress field through the whole weld depth [3-10]. However, all of these post-heat treatment processes are elaborate, rather cost-intensive or are, for example, in repairs, difficult to realize. Industry has been investing a lot of effort to improve the reliability of numerical simulation of its welding processes and post-weld treatment (PWT) in order to have a better understanding of the involved phenomena and also to predict the residual stress state through the structure [11-13]. This is crucial where high demand of security is imperative such as in nuclear applications where the material behavior of the weld may be significantly different from that of the wrought material [14]. Within the framework of the Task Group (TG4) of the NeT project (The European Network on Neutron Techniques Standardization for Structural Integrity), a three pass slot weld made from austenitic stainless steel AISI316L has been manufactured and the mechanical characterization by three-dimensional analyses of these residual stresses have been carried out by both experimental $[15,16]$ and numerical means [1]. Further mechanical treatment of the welds like finish milling additionally influence or change the final state of the residual stress distribution of the welded components and need to be considered and included in the final numerical simulation. Turning, similar to milling where the only difference is that the material stay static, may be the most studied process in literature. Since the early 1950s, researchers are trying to model and understand the severe mechanical and thermal effects occurring around the cutting edge and on the component surface. Turning is a process involving high temperatures and temperature gradients at the surface which can generate in many cases surface tensile residual stresses which decrease steeply with depth reaching a maximum of compressive residual stresses in the sub-surface layer [17-19]. New numerical simulations, using a dedicated hybrid method, specifically setup to simulate finish turning, subsequently applied to welding, have been developed to predict the final state in the component and its interaction with previous operations [20-22].

In this study, the effect of successive surface machining on the tensile residual stress after welding is non-destructively determined by neutron diffraction (ND) from the surface into the bulk using as a case study the austenitic stainless steel NeTTG4 round robin sample. In order to resolve the steep stress gradient close to the surface, one would need a small gauge volume in neutron diffraction experiment. However, the coarse grain nature of the weld as well as thickness of the sample did not allow measurements with resolution smaller than $1 \mathrm{~mm}$. Therefore, these measurements were conducted using an as big as reasonable gauge volume which was scanned through the surface and consequently was not always completely immersed in the material. The strain data were corrected for spurious strains, and data deconvolution of the expected steep strain gradients within the gauge volume were carried out according to [23]. The experimentally derived stress profile is then compared to x-ray diffraction (XRD) measurements obtained afterwards by electro-polishing layer removal technique at the same location up to $0.5 \mathrm{~mm}$ in depth as well as to predictions by finite element simulations (FEM) using the hybrid method. In addition, the neutron diffraction measurements are compared and discussed to the original as-welded stress state. For the determination of the stress profile using neutron diffraction in the as-welded state, the possible influence of texture and shear stresses were also investigated and discussed.

\section{Sample-welding and finish milling}

The specimen was produced according to the NeT-TG4 manufacturing protocol from a block of ITER material, an AISI type $316 \mathrm{~L}$ austenitic stainless steel and denominated as A2-2 [24]. The concentration of relevant chemical elements in this steel is given in Table 1.

All TG4 specimens were cut from the same large steel plate with similar orientation and machined to their final dimensions. Prior to welding, the plates were $18 \mathrm{~mm}$ thick, $150 \mathrm{~mm}$ wide, and $194 \mathrm{~mm}$ long (Fig. 1). The slot, to be filled with three weld beads, was centered on the top face and parallel to the plate's longitudinal edge. It was $80 \mathrm{~mm}$ long and $6 \mathrm{~mm}$ wide at the bottom, with a width of about $10 \mathrm{~mm}$ at the top. After machining, the samples were heated to $1050^{\circ} \mathrm{C}$ at a rate of $5{ }^{\circ} \mathrm{C} / \mathrm{min}$ to relief stress. This temperature was held for $45 \mathrm{~min}$, and then, the sample was subsequently furnace-cooled to $300{ }^{\circ} \mathrm{C}$. A detailed microstructure characterization can be found elsewhere $[15,16]$. A semi-automated Tungsten Inert Gas (TIG) welding process was used to deposit the three weld beads on top of each other. The $x, y$, and $z$ directions correspond to the transverse, normal, and longitudinal directions of the weld, respectively (see Fig. 1).

The finish milling operation was performed with tungsten carbide tool coated with TiN layer (TCMW 16 T3 08). The machining was done using a milling tool mounted on a milling

Table 1 Weight concentration of relevant chemical elements of the AISI type 316L studied steel

\begin{tabular}{llllllllll}
\hline Element & $\mathrm{C}$ & $\mathrm{Cr}$ & $\mathrm{Fe}$ & $\mathrm{Mn}$ & $\mathrm{Mo}$ & $\mathrm{Ni}$ & $\mathrm{P}$ & $\mathrm{Si}$ & $\mathrm{S}$ \\
\hline wt\% & 0.027 & 17.5 & $62-72$ & 1.7 & 2.47 & 12.5 & 0.045 & 0.37 & $<0.3$ \\
\hline
\end{tabular}


Fig. 1 Schematic representation of the weld at the plate to be measured. Measurements will be carried out at the BD-line, the interception line between the plane B and plane D (throughthickness). The $x, y$, and $z$ directions correspond to the transverse, normal, and longitudinal directions of the weld, respectively

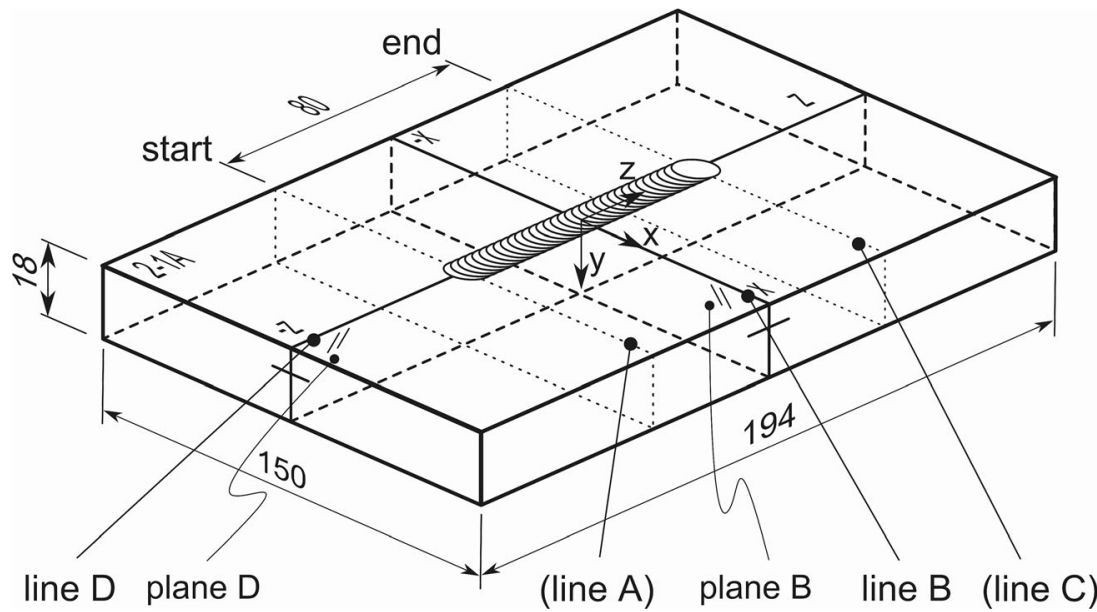

head (Fig. 2a). The finish milling cutting conditions were as follows: cutting speed $100 \mathrm{~m} \mathrm{~min}^{-1}$; feed per pass $0.45 \mathrm{~mm}$ $\operatorname{tr}^{-1}$; and depth of cut $0.3 \mathrm{~mm}$. Several passes were made before the last one in order to remove the excess of welding material (Fig. 2b).

Figure 3 shows macrostructures of the cross sections of the planes B (a) and D (b), respectively, from the plate after welding. Prior to the welding, the edges of the plates were machined to obtain rectangular and parallel edges for easier and more reproducible specimen mounting for the strain measurements. More details about the weld process and characterization can be found in $[15,16,25]$. The new surface after machining of the weld is at $1.6 \mathrm{~mm}$ depth relative to the initial weld surface.

\section{Finite element modeling}

Welding simulations require heat transfer and microstructure modifications, in order to obtain accurate residual stresses, and the whole structure model is often necessary in order to take into account its global stiffness. Details of the welding finite element simulation of the round robin sample can be found in the study of Muränsky et al. [25]. The close agreement between finite element simulation of Muransky et al. and experiment results without the need to use adjustable scaling parameters clearly validates the model.

On the other hand, the simulation of turning using the hybrid method is a local approach that considers only a small part of the workpiece [20]. Moreover, the main effect of machining is expected near the surface, and consequently, the mesh size in this area needs to be very small for the FEM simulation. Finally, considering the heat rate and maximal temperature reached during turning, the effect of metallurgical transformations is neglected for the turning simulation. On the contrary, a dependency with the deformation rate is required. The following paragraph will describe the procedure to transfer initial stress state fields after welding as initial states for the machining calculation. The mesh size for welding is about
Fig. 2 a Milling tool mounted on a milling head. b NeT-TG4, international benchmark weld plate after several passes of finish milling and by last machining state

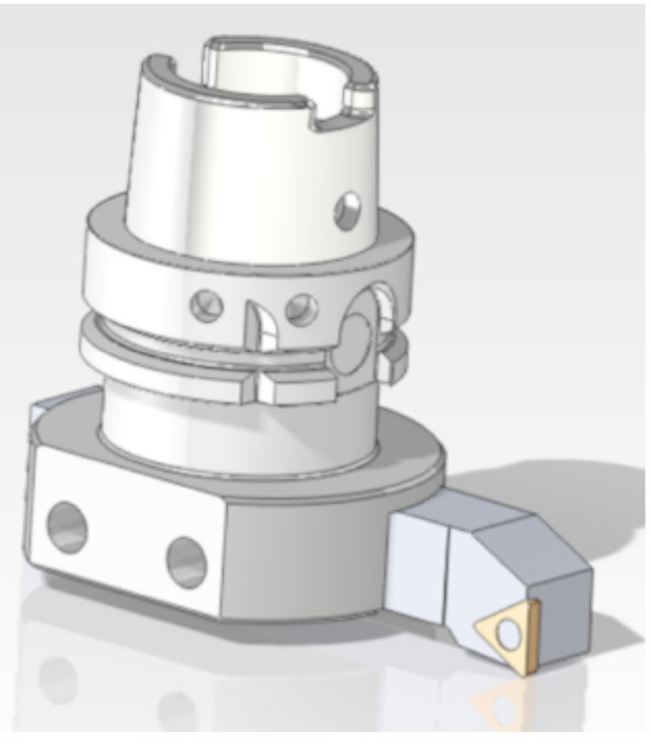

a

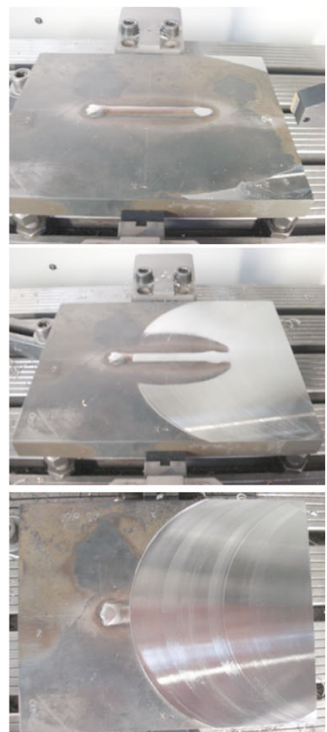

b 
Fig. 3 Cross section of the weld at the plane $\mathrm{B}(\mathbf{a})$ and $\mathrm{D}(\mathbf{b})$ respectively of the NeT-TG4, international benchmark plate described in detail by Smith et al. [15]

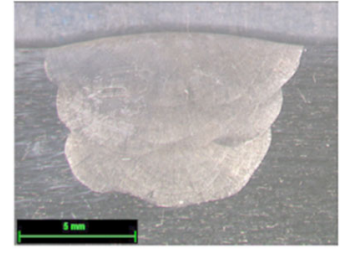

a

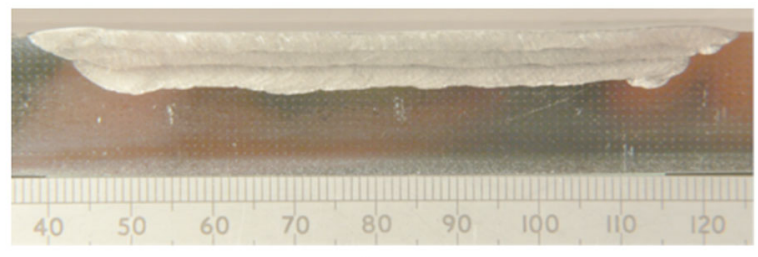

b
$1 \mathrm{~mm}$ in every direction whereas the mesh for machining requires a refinement near the surface down to a few micrometers under the machined surface. Therefore, the number of degrees of freedom for turning simulation is about six times the one required for welding even if the total dimension of the model is about twenty times smaller than the welding bead length.

In this study, the effect of machining is tested on the middle section of the welding joint. At this location, the welding has reached a steady state. Since all the calculations are performed assuming the small displacement hypothesis, only plastic deformation and hardening variables are required for mapping. The procedure to start from the welding simulation is as follows:

- data transfer from the welding model to the local model including the excess of bead material from welding,

- balancing of the results,

- trimming the excess bead over the plate reference top surface,

- balancing of the results,

- machining simulation.

The machining simulation considers the following conditions:

- cutting speed, $\mathrm{Vc}=100 \mathrm{~m} / \mathrm{min}$

- depth of cut $a_{\mathrm{p}} 0.3 \mathrm{~mm}$

- $\quad$ feed per pass, $f=0.3 \mathrm{~mm} / \mathrm{rev}$

Simulations of five passes are made on the local model. In order to chain simulations, the same material laws are considered and a dependency to the plastic strain deformation is added to account viscous effects during turning operation $[21,22]$.

\section{Diffraction measurements}

\subsection{X-ray diffraction}

The XRD stress analysis was performed according to the European Standard, NF EN 15305 (April 2009) [26]. Peak displacements of the $\gamma$-Fe $\{311\}$ diffraction plans were determined using $\mathrm{Mn} \mathrm{K} \alpha \mathrm{x}$-ray radiation with wavelength of $2.10314 \AA$, and the detector was at the $2 \theta$ position of $152.8^{\circ}$. The measurements were conducted in longitudinal and transverse directions. A pinhole collimator of $2 \mathrm{~mm}$ was used in the incident beam. The diffraction analysis was performed at the top surface, and it was continued in depth by material layer removal in steps of 5,15 , and $30 \mu \mathrm{m}$ until a penetration depth of $200 \mu \mathrm{m}$ was reached. From here, material removal was carried out in steps of $100 \mu \mathrm{m}$ until the final depth of 400 $\mu \mathrm{m}$. Data acquisitions were made for $8 \psi$ angles between \pm $30^{\circ}$ in theta mode using a Proto XRD machine. Radiocrystallographic elastic constants of (1/2) $\mathrm{S} 2{ }_{311}=7.52$ $\mathrm{E}^{-6}(1 / \mathrm{MPa})$ and $-\mathrm{S}_{311}=-1.80 \mathrm{E}^{-6}(1 / \mathrm{MPa})$ were used to calculate the residual stresses [27].

\subsection{Neutron diffraction}

The neutron diffraction measurements were carried out at the instrument STRESS-SPEC. This diffractometer is optimized for strain [27] and texture analysis [28]. Initial texture measurements on the base material were carried out using a $\operatorname{Ge}(311)$ monochromator $(\lambda=1.26 \AA)$ and the robot setup of STRESS-SPEC. Pole figures of the $\gamma$-Fe $\{111\}$ and $\{200\}$ were collected from cuboids $\left(5 \times 8 \times 6 \mathrm{~mm}^{3}\right)$ of the parent material. The cuboids were completely bathed in the neutron beam. For all residual stress measurements, the $\mathrm{Si}(400)$ monochromator was selected at a take-off angle of $2 \theta_{M}=75.90^{\circ}$ yielding a wavelength of approximately $1.67 \AA$. The diffraction peaks of the $\gamma$-Fe $\{311\}$ for the selected wavelength appears at ca. $2 \theta_{S} \sim 101.0^{\circ}$. Diffraction data were collected with a ${ }^{3} \mathrm{He}-\mathrm{PSD}$ detector with $1-\mathrm{mm}$ resolution and $256 \times 256$ $\mathrm{mm}^{2}$ dimensions [29]. Two different types of strain measurements were performed. The original TG4 three pass weld specimen A2-2 was measured along the BD-line through the depth of the sample using a relatively coarse step size to determine the as-welded stress state and identify the main strain directions. Then, the strains of the subsequent machined sample were measured along the main stress components determined previously for the as-welded state.

\subsubsection{Main axis of stress tensor}

In the study of residual stresses in welds, the common assumption is that the welding direction defines the principal 
components of the stress tensor. However, several authors have suggested that close to the weld start and stop regions as well as in the weld material, the principal component directions could be quite different from the geometrical parameters imposed by the welding process [16]. To verify if the main weld axes are indeed identical to the orientation of the principal stress components at the selected measuring position, measurements in the central part of the weld were carried out to determine the full stress tensor in the machined TG4 specimen along the BD-line. A gauge volume of $2 \times 2 \times 2 \mathrm{~mm}^{3}$ was used for the measurements. The elasticity constants of $\mathrm{E}_{311}=$ $175 \mathrm{GPa}$ and $v_{311}=0.31$ were used to calculate the respective residual stresses [30]. The sample was mounted in the $90^{\circ}$ cradle of STRESS-SPEC to allow arbitrary sample orientation with respect to the scattering vector in order to determine the full 3D stress tensor. As the sample is relatively coarsegrained, the sample was oscillated by $\pm 5^{\circ}$ around the scattering vector in order to improve grain statistics. To evaluate the residual stress by neutron diffraction, the strains must be measured in at least six independent directions. The specimen orientations are listed in Table 2.

Altogether, nine points were analyzed starting at a depth of $1 \mathrm{~mm}$ beneath the surface. A step size of $1 \mathrm{~mm}$ was used until $3 \mathrm{~mm}$ in depth, and afterwards, a step size of $2 \mathrm{~mm}$ was used until $15 \mathrm{~mm}$ depth.

\subsubsection{Main directions residual stresses}

The residual stresses in the main directions are calculated according to the following equation:

$$
\begin{aligned}
\sigma_{i} & =\frac{E_{\mathrm{hkl}}}{\left(1+v_{\mathrm{hkl}}\right)\left(1-2 v_{\mathrm{hkl}}\right)} \varepsilon_{i}+\frac{v_{\mathrm{hkl}} E_{\mathrm{hkl}}}{\left(1-2 v_{\mathrm{hkl}}\right)\left(1+v_{\mathrm{hkl}}\right)} \sum_{j} \varepsilon_{j}, j \\
& =1,2,3 \text { and } j \neq i
\end{aligned}
$$

where $\sigma_{i}$ and $\varepsilon_{i}$ are the principal stresses and strains. $E_{\mathrm{hkl}}$ and $\nu_{\mathrm{hk} 1}$ are the Young modulus and Poisson ratio for the direction perpendicular to the $\{\mathrm{hkl}\}$ diffraction planes. For the aswelded sample, the gauge volume was defined by a discrete variable primary slit and radial collimator with a full width at half maximum (FWHM) of $2 \mathrm{~mm}$ in the diffracted beam. In transverse and normal directions, the gauge volume was set to

Table 2 Choose angles to have the six measured independent directions

\begin{tabular}{llll}
\hline Position & $\varphi\left[^{\circ}\right]$ & $\chi\left[^{\circ}\right]$ & $\omega\left[^{\circ}\right]$ \\
\hline A & 0 & 180 & 0 \\
B & 0 & 150 & 0 \\
C & 0 & 180 & 90 \\
D & 0 & 90 & 0 \\
E & -12 & 170 & 0 \\
F & -20 & 105 & 0 \\
\hline
\end{tabular}

$2 \times 10 \times 2 \mathrm{~mm}^{3}$ while for the longitudinal direction, a $2 \times 2 \times$ $2-\mathrm{mm}^{3}$ gauge volume was used. Here the measurements were conducted in steps of $1 \mathrm{~mm}$, where 15 points along the plate cross section were acquired. For the welded and subsequently machined sample, a 1-mm radial collimator was used in the diffracted beam instead. Here the transverse and normal directions were acquired using a gauge volume of $1 \times 10 \times 1 \mathrm{~mm}^{3}$, and in the longitudinal direction, a $1 \times 5 \times 1-\mathrm{mm}^{3}$ gauge volume was defined. In both experiments, oscillations were mandatory to reduce detrimental effects on the measurements due to coarse grain material nature, a well-known problem in case of diffraction-based residual stress measurements in austenitic welds. Without oscillations, quite poor measurement statistics are achieved, since at any time, only a few grains are correctly oriented for diffraction. For the welded sample, a continuously $\pm 3^{\circ}$ oscillation was used. In case of the machined sample, a different approach was implemented. Depending on the measuring depth position, the sample was rotated around the scattering vector $\pm 6^{\circ}$ or even $\pm 11^{\circ}$ in discrete steps of $1^{\circ}$, thus yielding 13 and 23 independent measurements, respectively. These were fitted individually and a final value for the strain calculated on basis of this results. In this sample, due to the very coarse grains in the weld region, oscillations of $\pm 11^{\circ}$ were mandatory for measurement position down to around $800 \mu \mathrm{m}$, to obtain reasonable statistics. From that point onwards, measurements with $\pm 6^{\circ}$ oscillation were sufficient to obtain the desired statistics. The step size of the measurement positions in the machined sample was $0.1 \mathrm{~mm}$ form the surface down to $1.5 \mathrm{~mm}$. From there, the step size was increased to $1 \mathrm{~mm}$ through the plate cross section until $12 \mathrm{~mm}$ in depth.

Reference cuboids were measured to calculate the reference values, $2 \theta_{0}$. One cuboid was taken from the parent material (austenitic steel AISI 316L extracted from the plates as received and after the stress-relief heat treatment), the second one from the top of the weld, and the last one from the bottom of the weld. Each cuboid has a volume of $5 \times 8 \times 6 \mathrm{~mm}^{3}$ and is produced by gluing together four small sub-cuboids with dimensions $5 \times 4 \times 3 \mathrm{~mm}^{3}$ (see also [16]).

\subsubsection{Evaluation of intrinsic strain distributions}

The neutron experimental data are analyzed using the semiempirical method proposed by Saroun et al. [23, 31]. The method provide tools for analysis of residual strains whenever measurements close to a surface are performed and pseudo strains must be accounted for. The method treats pseudo strains due to partial immersion of the sampling volume in the sample, and can also be used in case of steep intrinsic strain gradients. The method employs a convolution method, which uses sampling points produced by Monte Carlo raytracing simulation [32] of the diffractometer within the gauge volume, to model smearing effects by the instrumental 
response, e.g., wavelength spread within the incident beam, geometrical and peak clipping effects [33, 34]. Each point has all available information about a scattering event: position, initial and final neutron wave vector, probability and lattice spacing value, $d_{\mathrm{hkl}}$, associated with this sampling point. This sampling distribution is then reused, to carry out the convolution with any sample shape, position, orientation, and strain distribution. The sampling distribution is defined by a list of coordinates of possible scattering events, including the depth under the sample surface, $i$; the probability of the event,

; and the associated instrumental peak shift, usually called spurious strains, . Given the intrinsic distributions of lattice strain $\varepsilon(z)$ and scattering probability $S(z)$, the smeared strain distribution, $\varepsilon_{S}(z)$, is produced as a sum over the simulated events,

$\varepsilon_{S}(z)=\sum_{i} p_{i} A_{i} S\left(z-z_{i}\right)\left[\varepsilon\left(z-z_{i}\right)+\epsilon_{i}\right]$

where $A_{i}$ is the beam attenuation factor calculated for each event from the neutron trajectories and sample geometry. More details can be seen in [35]. Using the model to fit, the observed intensity profile yields the necessary free parameters, such as the real gauge volume size, surface position, and attenuation coefficient. Therefore, no extra calibration measurements are necessary. However, with strong variation of scattering probability, e.g., due to texture, plastic deformation, or composition gradients near the surface, it is not always possible to determine the surface positions through the usual intensity variation [35]. Like this, it must be determined independently — in our case by optical means - and kept fixed for the strain fits with this model.

\section{Results and discussion}

\subsection{X-ray diffraction}

In Fig. 4, the measured XRD residual stress profiles and full width at half maximum (FWHM) of the $\mathrm{Fe}(311)$ diffraction peak are plotted for the longitudinal and transverse directions as function of depth. The results show that the finish milling introduces compressive residual stresses just below the surface from around $50 \mu \mathrm{m}$ into the depth, highlighting considerable alteration of the initial tensile residual stress introduced by the welding procedure. Up to about approximately $250 \mu \mathrm{m}$ in depth the FWHM of the Bragg reflection is broadened, indicating work hardening [36]. The maximum values at the surface are similar to the ones obtained by Outeiro et al. [18] after identical turning process parameters at the same material.

At the present study, two different slops are observed, first until around $100 \mu \mathrm{m}$ and the second until $250 \mu \mathrm{m}$. The first slope is identical to the one observed after turning [18]. The affected depth corroborates the microstructure of an identical parent material stainless steel AISI316L obtained under similar finish turning conditions as for the present study, see Fig, 5 . The second slop is probably related to the welding process before the finish turning. The weld influence is still visible from around $250 \mu \mathrm{m}$ upwards due to the again increasing tensile nature of the stress profile. The calculated stress errors are around $\pm 40 \mathrm{MPa}$ down to a depth of $50 \mu \mathrm{m}$ and then increase to significant higher error values up to $\pm 300 \mathrm{MPa}$. This is most likely an effect of the relatively coarse grain structure in the weld zone leading to possible peak extinction in the $\sin ^{2} \psi$ line. This also makes XRD measurements in larger depth in austenitic steel weld increasingly difficult and unreliable [37].

\subsection{Neutron diffraction}

Initial pole figure measurements show that the texture is weak with a multiple of randomness (m.r.d.) close to 1.0, which sets aside texture-related effects on the residual stress measurements. Furthermore, even if the texture would be sharper, it was shown recently in the case of austenitic cladded layers that for the $\gamma-\mathrm{Fe}\{311\}$ diffraction line, the influence of the texture on the anisotropy of the Young modulus and the resulting residual stress values is below $10 \%$ [38].

In Fig. 6a, the shearing stresses are plotted for different positions along the BD-line. In the figure, $\sigma_{12}, \sigma_{13}$, and $\sigma_{23}$ are the shear stresses where the main stresses are $\sigma_{11}, \sigma_{22}$, and
Fig. 4 Residual stress (full symbols) and FWHM (open symbols) profiles in depth for the longitudinal (a) and transverse (b) directions obtained by XRD for the BD-line

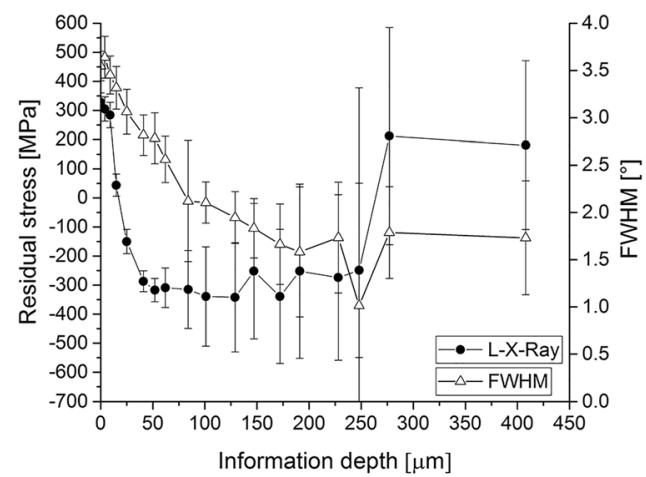

a

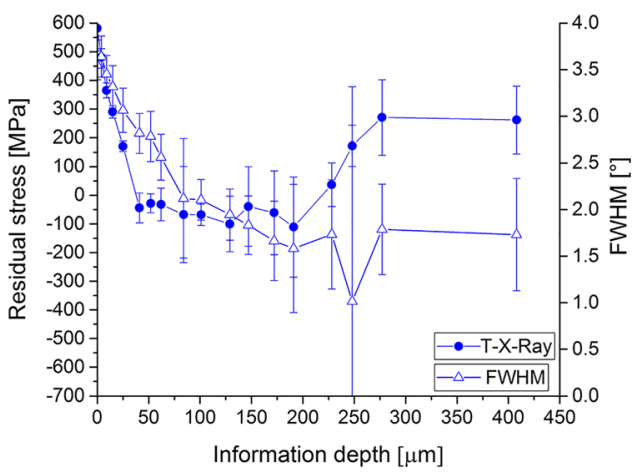

b 
Fig. 5 Microstructure of stainless steel AISI306L after finish turning with cutting speed $V \mathrm{c}=$ $200 \mathrm{~m} / \mathrm{min}$, depth of cut $a_{\mathrm{p}}=0.3$ $\mathrm{mm}$, feed per pass, $f=0.3 \mathrm{~mm} / \mathrm{rev}$

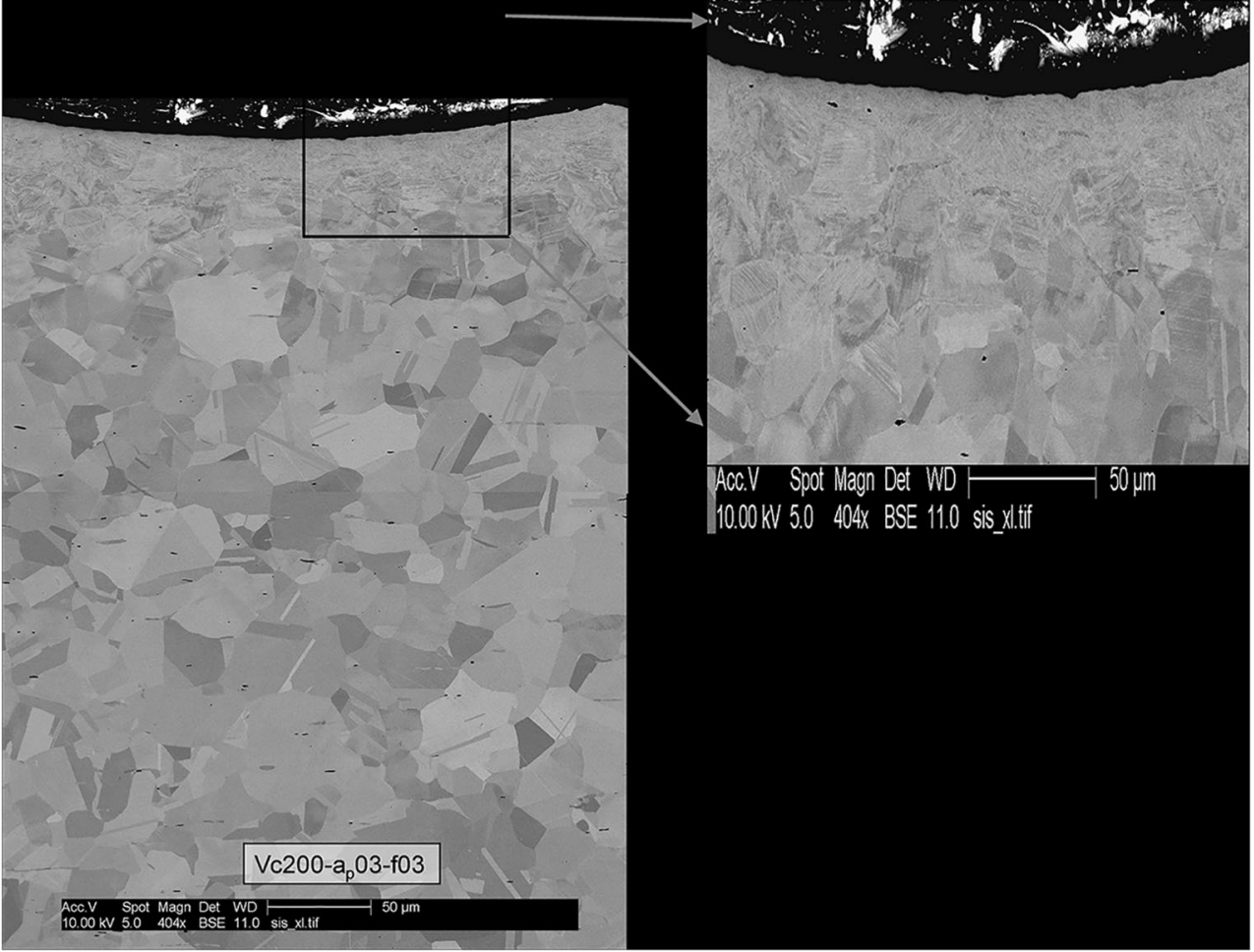

$\sigma_{33}$. The main stress in transversal direction along the $x$-axis of the sample coordinate system corresponds to $\sigma_{11}, \sigma_{22}$ is the strain in longitudinal direction along the $z$-axis, and $\sigma_{33}$ is the stress in normal direction along the $y$-axis. The shearing components of the stress tensor are found to be small, in the order of $\pm 100 \mathrm{MPa}$, see Fig. 6a. This supports the assumption that the principal stress components are approximately aligned with the main weld directions (longitudinal, transverse, and normal). Moreover, the calculated torsion angles, $\alpha, \beta$, and $\gamma$ are around $0^{\circ}$ and $90^{\circ}$, confirming this assumption. The calculated residual stresses for the main directions with and without consideration of shear stress are depicted in Fig. 6b.

Comparison of the curves shows the minor influence of the shear stresses on the values of the residual stresses. The largest discrepancies up to $50 \mathrm{MPa}$ are found in the region of the weld, and the weld boundaries are suggesting this to be rather an effect of the large grain sizes in the weld.

Hence, the following strain measurements were carried out only in the three directions coinciding with the main weld directions, longitudinal, transverse, and normal. In Fig. 7, the respective calculated residual stress profiles in depth along the BD-line are shown for the as-welded and the machined sample for the three main directions.

For the as-welded sample, the residual stress profiles, for longitudinal and transverse directions, show tensile behavior with a maximum longitudinal residual stress of $425 \mathrm{MPa}$ and a maximum transversal stress $225 \mathrm{MPa}$ in approximately 9 and $5 \mathrm{~mm}$ depth, respectively. These results are in excellent agreement with the round robin study conducted on NeT-TG4 specimen at different neutron diffractometers around the world
Fig. 6 a Calculated shear stresses for different measuring positions along the BD-line. The zero position is at the surface of the weld. b Calculated residual stresses for the main weld directions: longitudinal (L), traverse $(\mathrm{T})$, and normal $(\mathrm{N})$, considering the measured shear stress (dashed lines) and without (full symbols and continuous lines)

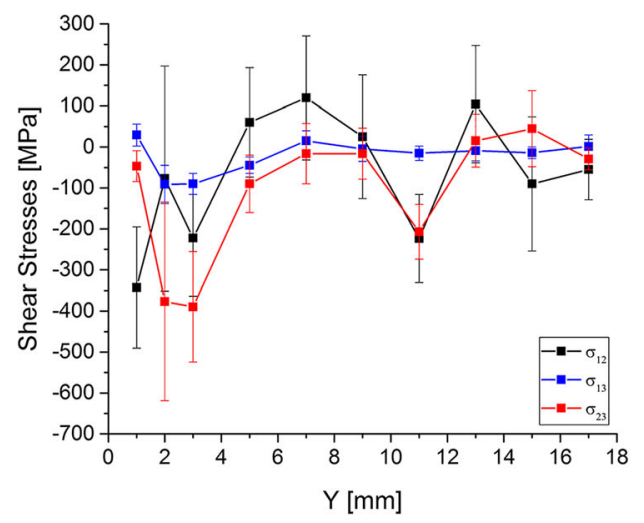

a

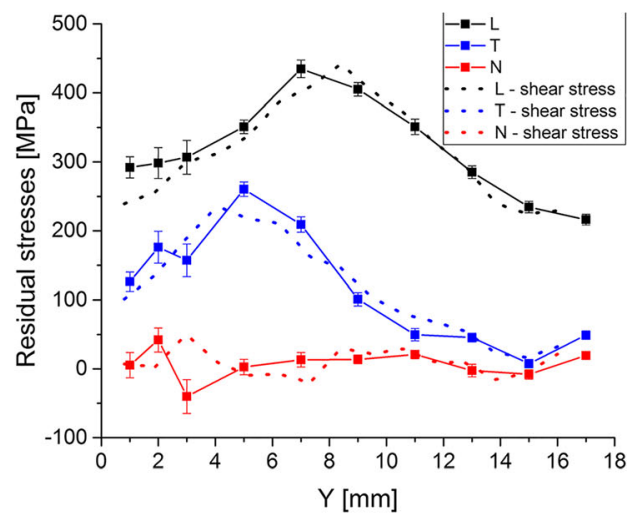

b 


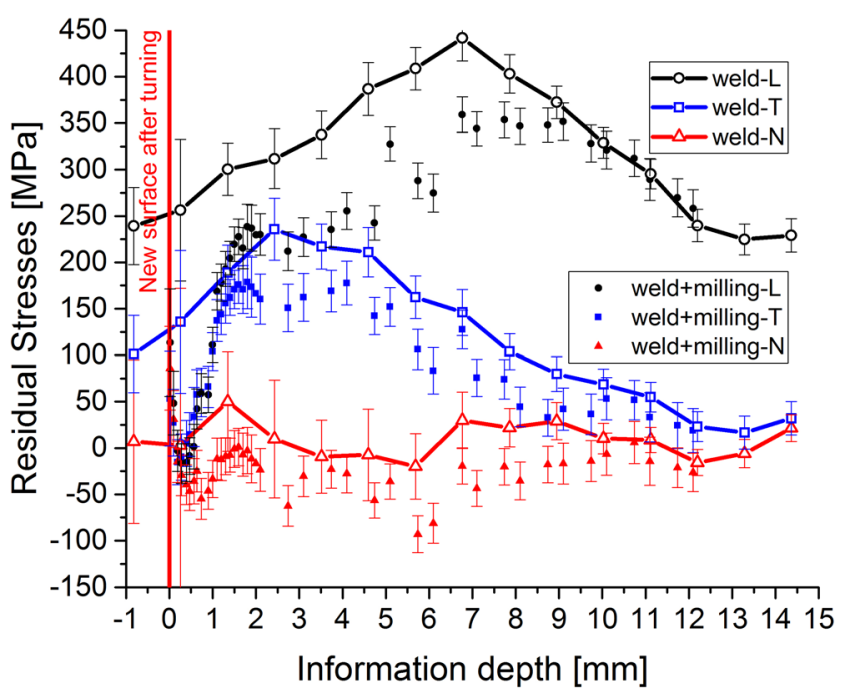

Fig. 7 Residual stress profiles along the BD-line for the as-welded (open symbols) and as-welded plus machined (full symbols) samples

[15]. The stresses calculated directly from the measured strains for the machined sample are also plotted in the same figure for comparison. It is important to note that close to the surface, due to the relatively large gauge volume size, the centroid of the gauge volume does not coincide with the center of the irradiated material [33].

The depth positions of the measurement points in the figure are already adjusted to incorporate this geometrical shift, and they are thus referred to as information depth. Only the measuring points in depths smaller than $1 \mathrm{~mm}$ were not totally immersed in the material and had to be corrected for respective spurious strains. This is the depth until where the finite element simulations show the steep stress variations in profile, from tensile values at the surface, decreasing very steeply to compression and increasing again until positive values are reached again [21]. To allow comparisons of the surface details, the following figures show therefore only the results of data fitting until $2 \mathrm{~mm}$ depth. In Fig. 8, the measured strains and error bars are shown together with fitted curves (lines).

The strain distributions were fitted with the function $\varepsilon_{S}(z)$ from Eq. (1), where the intrinsic strain ( $z$ ) was modeled by a set of $\left(z_{\mathrm{j}}, \varepsilon_{\mathrm{j}}\right)$ nodes set as free variables, connected by piecewise cubic polynomial interpolation. Two model settings were considered: (a) a free model $\varepsilon(z)$ curve determined by six $\left(z_{\mathrm{j}}\right.$, $\varepsilon_{\mathfrak{j}}$ ) nodes, and (b) a model, where the strain at the surface was constraint to the value derived from the XRD measurement with the remaining values down to $15 \mathrm{~mm}$ depth being freely adjustable parameters as in the previous case. It is worth noting that the experimental error bars are not derived from the fitting uncertainties of peak positions alone, but were calculated considering extra random uncertainty contribution from the grain size statistics due to the coarse grain nature of the weld material [39]. Very good agreement of the fits with the experimental data was achieved in both cases; however, the respective deconvoluted (intrinsic) strain profiles shown in Fig. 9a show considerable differences between the two model settings for depths smaller than about $0.5 \mathrm{~mm}$.

This is especially visible for the transverse direction in the amplitude and the surface values of the strains. This figure also demonstrates the level of uncertainty one has to consider when interpreting the analyzed results obtained by ND from the surface until the bulk. Nevertheless, the achievements are appreciable if the sample characteristics, coarse grain, and resolution achieved are considered. Both results show compressive strains/stresses immediately beneath the surface with a minimum around 0.3 to $0.4 \mathrm{~mm}$ depth. This was not as clearly visible in the uncorrected stress profiles derived directly from the measurement data, see Fig. 7. The width of the compressive stressed zone is roughly comparable with the XRD results; however, the position of the minimum is about $150-250 \mu \mathrm{m}$ deeper in the component. This is clearly an effect of missing information in the experimental data at the depths much smaller than the gauge volume size. When only part of the nominal gauge volume is buried in the material, the true sampling volume becomes smaller and actual spatial resolution is better that the nominal one ( $1 \mathrm{~mm}$ in this experiment). However, the Monte Carlo ray-tracing simulations of the sampling volume show that, in practice, the resolution cannot be better than about $30 \%$ of the nominal value, i.e., about 0.3 $\mathrm{mm}$. Features of the strain distribution on a smaller size scale cannot be distinguished. A better result could only be
Fig. 8 Strain profiles along the BD-line of the welded plus machined sample for the three main directions: longitudinal, transverse, and normal. Points are the neutron diffraction measurements, and the lines are the fits obtained for a free model (a) and a model fixed to XRD values at the surface (b)

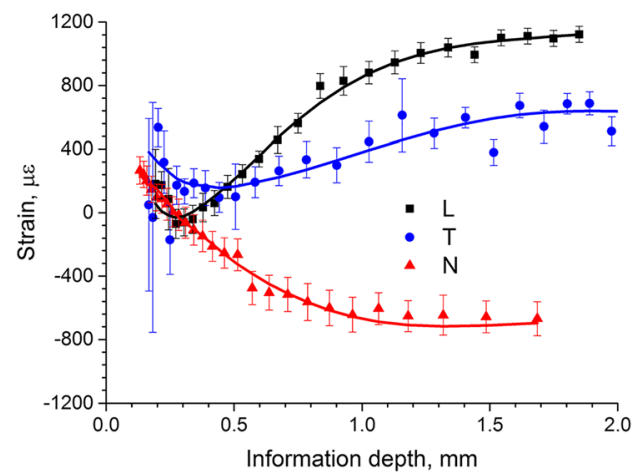

a

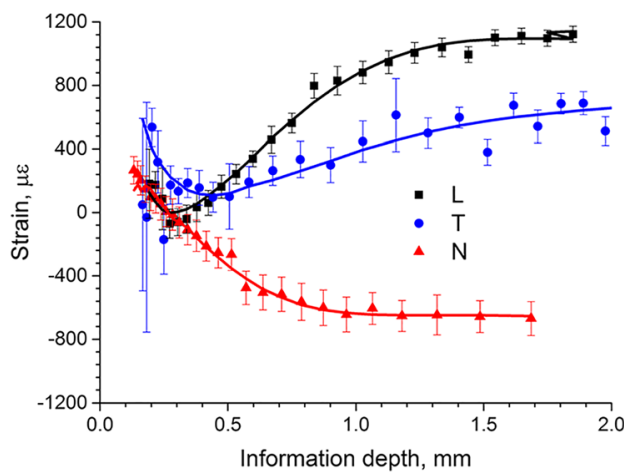

b 
Fig. 9 Deconvoluted residual strain (a) and stress (b) profiles corresponding to the fits in Fig. 9, free model (solid lines) and constraint model fixed to the surface XRD value (dashed lines). The error bars indicate $1 \sigma$ confidence limits estimated by the bootstrap method [35]

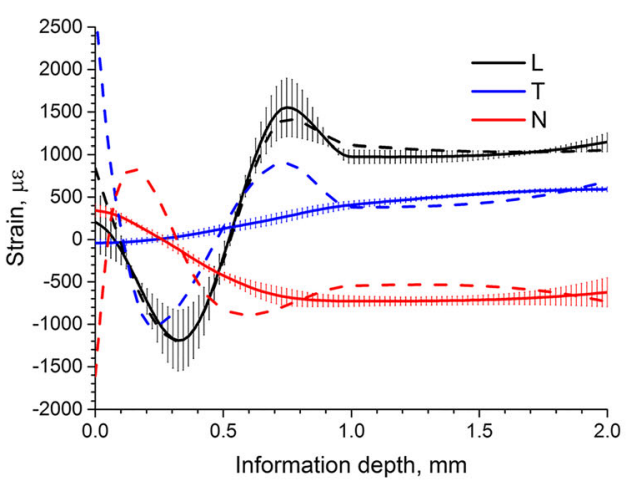

2

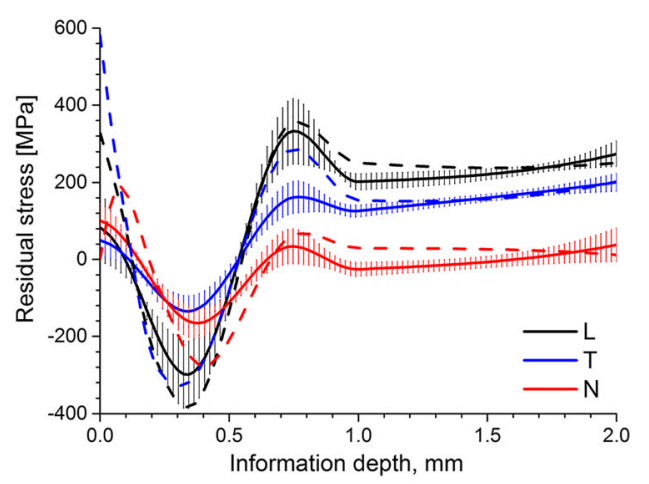

b achieved if additional information is provided and implemented as a constraint in the fitting procedure, i.e., using the results of the XRD measurements at the surface. Uncertainty of the exact surface position is another obstacle in the data analysis. Because of the large grain size, the surface position could not be determined from the usual entering scan intensity profiles for transmission and reflection geometries. Therefore, the sample surface was determined by optical means through a theodolite. An uncertainty of $\pm 0.2 \mathrm{~mm}$ is typically associated with this optical alignment method, and therefore, its influence on the fitted strain profiles was also checked. Figure 10 shows the results for the longitudinal strain component and for sample position varied by $\pm 0.2 \mathrm{~mm}$ with respect to the optically determined surface position. In Fig. 10, it is apparent that the form of the resulting profiles is nearly independent of the surface positions, i.e., the amplitude of the strains (difference from the minimum and maximum strain value), the width of the compressive part of profile, and the tensile strain value at the surface are roughly constant. However, the position of the minimum in compressive stress is clearly most affected as expected.

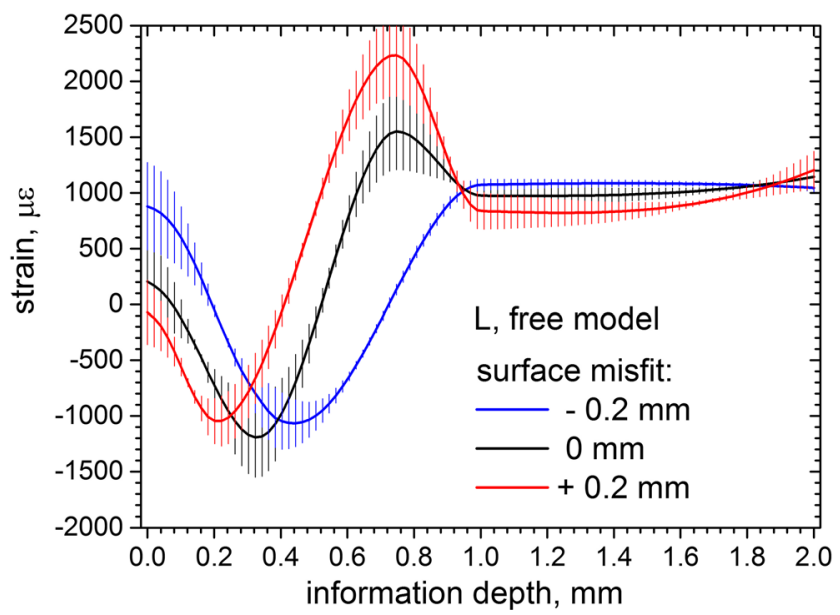

Fig. 10 Strain profiles along the BD-line for the longitudinal direction of the welded plus machined sample calculated by the code, considering different sample surfaces positions
The residual stress profiles in depth determined using $\mathrm{X}$-ray and neutron diffraction as well as the FEM simulation results are compared in Fig. $11 \mathrm{a}$ and $\mathrm{b}$ for longitudinal and transverse directions, respectively. Both the original measured neutron data points and the resulting stress profiles after deconvolution and correction for spurious strains are shown. When the model is constrained (i.e., the value at the sample surface is fixed to the value derived from the XRD measurements), a steep surface residual stress gradient is observed reaching from tensile residual stress values at the surface to compressive stresses within a depth of approximately $300 \mu \mathrm{m}$.

However, the observed larger residual stress minimum value would lead to slightly higher stress values than the compressive yield strength of the material of approximately $310 \mathrm{MPa}$. Comparable compressive residual stress values have been already experimentally registered in similar materials, AISI316L and AISI316, and can be justified if the materials undergo plastic deformations [40]. Due to the sample characteristics, mentioned above, and the respective uncertainty on the surface position assessment, the neutron analysis presented in the above figure is closer to the XDR results if the surface misfit would be $+0.2 \mathrm{~mm}$. When the constrained model is used the absolute values of stress show clearly good agreement at the surface, however, transverse direction seems to overestimate the compressive residual stress. On the other hand, the unconstrained model yields absolute values consistent with all other analysis, except for values right at the surface, illustrating ND limitations. The underestimation of the longitudinal residual stress by the FEM simulations can be due to the use of available experimental 2D orthogonal cutting forces instead of real present repartition of $3 \mathrm{D}$ pressures cutting forces, reproducing better the real mechanic. This is still under investigation.

The quantitative differences observed between the experimental profiles and FEM simulations can be distinctly justified depending on the analysis method. Despite the observed differences, all experimental methods picture the same residual stress profile form as the FEM simulation: tensile residual stresses at the surface, a steep residual stress gradient in depth 
Fig. 11 Longitudinal (a) and transverse (b) residual stress profiles along the BD-line of the welded plus machined sample measured by $\mathrm{x}$-ray and neutron diffraction. Comparisons with finite element modeling and neutron spurious strain corrections and data deconvolution within the gauge volume are as well pictured

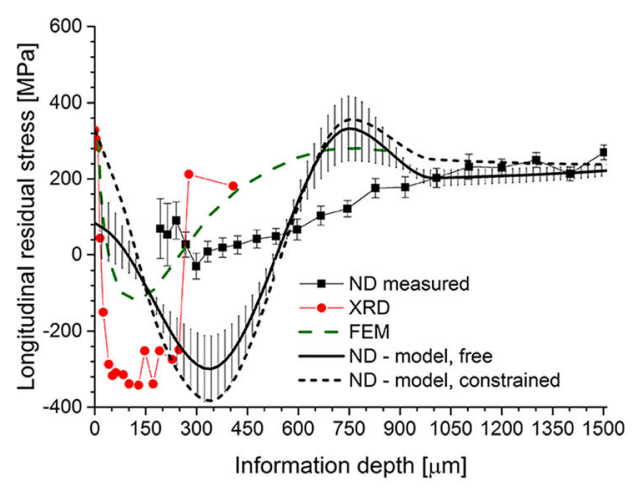

a

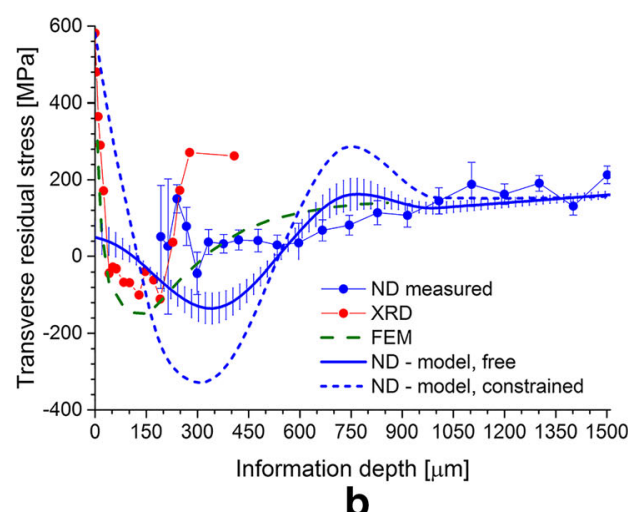

b reaching a maximum compressive residual stress underneath the surface, for depths smaller than $0.3 \mathrm{~mm}$ and tensile residual stress at a depth of approximately $1 \mathrm{~mm}[21]$.

\section{Conclusions}

In this study, a finite element model by successive chained simulation using a new hybrid method was experimentally verified by diffraction means using $\mathrm{x}$-ray and neutron diffraction. Experimental determination of the residual stress profiles for the main directions (longitudinal, transverse, and normal) in order to predict the final residual stress fields including finish milling after welding was possible. For the first time, experimental assessment of the residual stress profiles through a welded plate cross section, from the surface into the bulk, was possible non-destructively and with high spatial resolution using the neutron diffraction method. The results show that, apart from the first few microns, the mitigation of the tensile residual stresses after welding is achieved by finish milling. Therefore, depending on machining parameters, previous welding conditions, and design considerations, the extension of beneficial compressive residual stresses plateau can be exploited in future welding applications.

Funding information Open Access funding provided by Projekt DEAL. This study received funding provided by the German Research Foundation (DFG) within the project HO 3322/4-1 and GI 376/11-1. Moreover, Jan Saroun also received support through Czech Science Foundation project no. 16-08803J.

\section{Compliance with ethical standards}

Conflict of interest The authors declare that they have no conflict of interest.

Open Access This article is licensed under a Creative Commons Attribution 4.0 International License, which permits use, sharing, adaptation, distribution and reproduction in any medium or format, as long as you give appropriate credit to the original author(s) and the source, provide a link to the Creative Commons licence, and indicate if changes were made. The images or other third party material in this article are included in the article's Creative Commons licence, unless indicated otherwise in a credit line to the material. If material is not included in the article's Creative Commons licence and your intended use is not permitted by statutory regulation or exceeds the permitted use, you will need to obtain permission directly from the copyright holder. To view a copy of this licence, visit http://creativecommons.org/licenses/by/4.0/.

\section{References}

1. Sule J, Ganguly S, Suder W, Pirling T (2016) Effect of highpressure rolling followed by laser processing on mechanical properties, microstructure and residual stress distribution in multi-pass welds of 304L stainless steel. Int J Adv Manuf Technol 86:21272138

2. Lu ZM, Shi LM, Zhu SJ, Tang ZD, Jiang YZ (2015) Effect of high energy shot peening pressure on the stress corrosion cracking of the weld joint of 304 austenitic stainless steel. Mater Sci Eng A 637: 170-174

3. Asif MM, Shrikrishna KA, Sathiya P (2016) Effects of post weld heat treatment on friction welded duplex stainless steel joints. J Manuf Process 21:196-200

4. Kožuh S, Goji'c M, Kosec L (2009) Mechanical properties and microstructure of austenitic stainless steel after welding and postweld heat treatment. Kov Mater Met Mater 47:253-262

5. Kose C, Kacar R (2014) The effect of preheat \& post weld heat treatment on the laser weldability of AISI 420 martensitic stainless steel. Mater Des 64:221-226

6. Chen B, Skouras A, Wang YQ, Kelleher JF, Zhang SY, Smith DJ, Flewitt PEJ, Pavier MJ (2014) In situ neutron diffraction measurement of residual stress relaxation in a welded steel pipe during heat treatment. Materials Science \& Engineering, A: Structural Materials: Properties, Microstructure and Processing 590:374-383

7. Zhang JY, Huang B, Wu QS, Li CJ, Huang QY (2015) Effect of post-weld heat treatment on the mechanical properties of CLAM/316L dissimilar joint. Fusion Eng Des 100:334-339

8. Fu HY, Nagasaka T, Kometani N, Muroga T, Guan WH, Nogami S, Yabuuchi K, Iwata T, Hasegawa A, Yamazaki M, Kano S, Satoh Y, Abe H, Tanigawa H (2015) Effect of post-weld heat treatment and neutron irradiation on a dissimilar-metal joint between F82H steel and 316L stainless steel. Fusion Eng Des 98-99:1968-1972

9. Xin JJ, Fang C, Song YT, Wei J, Xu S, Wu JF (2017) Effect of post weld heat treatment on the microstructure and mechanical properties of ITER-grade $316 \mathrm{LN}$ austenitic stainless steel weldments. Cryogenics 83:1-7 
10. Ghorbani S, Ghasemi R, Ebrahimi-Kahrizsangi R, HojjatiNajafabadi A (2017) Effect of post weld heat treatment (PWHT) on the microstructure, mechanical properties, and corrosion resistance of dissimilar stainless steels. Materials Science \& Engineering, A: Structural Materials: Properties, Microstructure and Processing 688:470-479

11. Robin V, Nélias D, Zain-Ul-Abdein M, Maisonnette D, Feulvarch E, Roux JC, Bergheau JM, Hamdi H, Valiorgue F, Mabrouki T, Bruchon J, Pino Munoz D, Kermouche G, Xie J, Walter-Le-Berre H, Ichikawa Y, Ogawa K, Drapier S (2014) Thermomechanical industrial processes-modeling and Numerical Simulation: ISTE Wiley Publishing, edited by J.M. Bergheau 1-74. https://doi.org/ 10.1002/9781118578759.ch1

12. Gilles P, Courtin S, Robin V, Yescas M, Gommez F (2013) Paper PVP2013-97475, Proceedings of ASME 2013 Pressure Vessels and Piping Conference Volume 6B: Materials and Fabrication. ASME, Paris, France

13. Mourgue P, Robin V, Gilles P, Gommez F, Brosse A, Gallée S (2014) Paper PVP2014-28151, Proceedings of ASME 2014 Pressure Vessels and Piping Volume 6B: Materials and Fabrication ASME. Anaheim, California, USA

14. Gill T, Vijayalakshmi M, Rodriguez P, Padmanabhan KA (1989) On microstructure-property correlation of thermally aged type $316 \mathrm{~L}$ stainless steel weld metal. Metall Trans A 20A:1115

15. Smith MC, Smith A, Wimpory RC, Ohms C (2015) A Review of the NeT TG4 International Weld Residual Stress Benchmark, Paper PVP2015-45801 Proceedings of ASME 2015 Pressure Vessels and Piping Conference, Volume 6B: Materials and Fabrication, Boston, Massachusetts, USA

16. Martins RV, Ohms C, Decroos K (2010) Full 3D spatially resolved mapping of residual strain in a $316 \mathrm{~L}$ austenitic stainless steel weld specimen. Mater Sci Eng A 527:4779-4787

17. M'Saoubi R, Outeiro JC, Changeux B, Lebrun JL, Dias AM (1999) Residual stress analysis in orthogonal machining of standard and resulfurized AISI 316L steels. J Mater Process Technol 96(1-3): 225-233

18. Outeiro JC, Dias AM, Lebrun JL, Astakhov VP (2002) Machining residual stresses in AISI 316L steel and their correlation with the cutting parameters. Mach Sci Technol 6(2):251-270

19. Outeiro JC, Umbrello D, M'Saoubi R, Jawahir IS (2015) Evaluation of present numerical models for predicting metal cutting performance and residual stresses. Mach Sci Technol 19(2):183216

20. Valiorgue F, Rech J, Hamdi H, Gilles P, Bergheau JM (2012) 3D modeling of residual stresses induced in finish turning of an AISI304L stainless steel. Int J Mach Tool Manu 53:77-90

21. Valiorgue F, Brosse A, Robin V, Gilles P, Rech J, Bergheau JM (2013) Chained welding and finish turning simulations of austenitic stainless steel components, Proceedings of ASME 2013 Pressure Vessels and Piping Conference, Volume 6A: Materials and Fabrication, Paris, France

22. Valiorgue F (2008) Simulation des processus de génération de contraintes résiduelles en tournage du 316L. Nouvelle approche numérique et expérimentale. Thése de doctorat, Ecole Nationale Supérieure des Mines de Saint-Etienne

23. Šaroun J, Rebelo Kornmeier J, Gibmeier J, Hofmann M (2018) Treatment of spatial resolution effects in neutron residual strain scanning. Phys B Condens Matter 551:468-471

24. Haig R (2008), report at the NeT 13th Steering Committee Meeting in Lyon, France
25. Muránsky O, Smith MC, Bendeich PJ, Holden TM, Luzin V, Martins RV, Edwards L (2012) Comprehensive numerical analysis of a three-pass bead-in-slot weld and its critical validation using neutron and synchrotron diffraction residual stress measurements. Int J Solids Struct 49:1045-1062

26. European standard NF EN 15305, April 2009. NondestructiveTesting — Test method for residual stress analysis by $\mathrm{X}$-ray diffraction

27. Eigenmann B, Macherauch E (1996) Rontgenographische Untersuchung von Spannungszustanden in Werkstoffen Teil 111, Material-wissenschaft u. Werkstofftech. 27:426-437

28. Brokmeier H-G, Gan WM, Randau C, Völler M, Rebelo Kornmeier J, Hofmann M (2011) Texture analysis at neutron diffractometer STRESS-SPEC. Nucl Inst Methods Phys Res A 642:87-92

29. Rebelo Kornmeier J, Hofmann M, Gan WM, Randau C, Braun K, Zeitelhack K, Defendi I, Krueger J, Faulhaber E, Brokmeier H-G (2017) New developments of the materials science diffractometer STRESS-SPEC. Mater Sci Forum 905:151-156

30. Hofmann M, Gan WM, Rebelo Kornmeier J (2015) STRESSSPEC: materials science diffractometer. J Large-scale Res Fac 1:A1

31. Šaroun J, Rebelo Kornmeier J, Hofmann M, Mikula P, Vrana M (2013) Analytical model for neutron diffraction peak shifts due to the surface effect. J Appl Crystallogr 46:628-638

32. Šroun J, Kulda J (2008) Raytrace of neutron optical systems with RESTRAX. In: Erko A, Idir M, Krist T, Michette A (eds) Modern developments in X-ray and neutron optics. Vol. 137 of Springer Series in Optical Sciences. Springer-Verlag, Berlin, Germany, pp $57-68$

33. Hutchings MT, Withers PJ, Holden TM, Lorentzen T (2005) Introduction to the characterization of residual stresses by neutron diffraction. CRC 228 Press, Taylor and Francis, London

34. Webster PJ, Mills G, Wang XD, Kang WP, Holden TM (1995) Impediments to efficient through-surface strain scanning. J Neutr Res 3:223-240

35. Rebelo Kornmeier J, Hofmann M, Luzin V, Gibmeier J, Šaroun J (2019) Fast neutron surface strain scanning with high spatial resolution. Mater Charact 154:53-60

36. Prevey PS (1996) X-ray diffraction-residual stress techniques. In: Metals Handbook, 10. American Society for Metals, Metals Park, pp 380-392

37. Marques MJ, Ramasamya A, Batista AC, Nobrea JP, Loureiro A (2015) Effect of heat treatment on microstructure and residual stress fields of a weld multilayer austenitic steel clad. J Mater Process Technol 222:52-60

38. Fu JW, Yang YS, Guo JJ, Ma JC, Tong WH (2009) Microstructure evolution in AISI 304 stainless steel during near rapid directional solidification. Mater Sci Technol 25:1013-1016

39. Rebelo Kornmeier J, Gan WM, Marques MJ, Batista AC, Hofmann M, Loureiro A (2017) Texture characterization of stainless steel cladded layers of process vessels. Mater Sci Forum 879:1588-1593

40. Wimpory RC, Martins RV, Hofmann M, Rebelo Kornmeier J, Moturu S, Ohms C (2018) A complete reassessment of standard residual stress uncertainty analyses using neutron diffraction emphasizing the influence of grain size. Int J Press Vessel Pip 164:80 92

Publisher's note Springer Nature remains neutral with regard to jurisdictional claims in published maps and institutional affiliations. 